\title{
Autonomic nervous system dysfunction in Parkinson's disease: relationships with age, medication, duration, and severity
}

J Gert van Dijk, Joost Haan, Koos Zwinderman, Berry Kremer, Bob J van Hilten, Raymund A C Roos

\begin{abstract}
Heart rate variability at rest, during deep breathing, or standing up and with the Valsalva manoeuvre did not differ significantly between 67 patients with idiopathic Parkinson's disease (PD) and 31 healthy age matched controls. Blood pressure (BP) responses to standing up and sustained handgrip revealed diminished autonomic function in the PD group. In a preliminary analysis of the PD group older age, anti-Parkinson medication and higher Hoehn and Yahr (HY) stages were each associated with poor autonomic responsiveness. Disease duration was only related to the systolic BP fall on standing up. Multiple stepwise regression analysis showed that older age explained most of the variance of heart rate variability (up to $36 \%$ ), and the only significant $P D$ related factor was the use of medication, which explained less than $7 \%$. The HY stage accounted for $12 \cdot 7 \%$ of the variance in the standing up BP test, and the use of medication explained $10.6 \%$ of the variance of the systolic BP change in the sustained hand grip test. The unmedicated PD subgroup $(n=33)$, who had mild disease of short duration, showed no evidence of autonomic dysfunction. Cardiovascular autonomic dysfunction in PD is mild, mainly affects blood pressure responses, and occurs only in advanced cases.
\end{abstract}

( $F$ Neurol Neurosurg Psychiatry 1993;56:1090-1095)

It has been established that patients with Parkinson's disease (PD) frequently have autonomic nervous system dysfunction. ${ }^{1-19}$ Although methods and results vary between studies, there is strong evidence that parasympathetic as well as sympathetic function may be impaired in PD. Table 1 summarises findings of earlier reports on autonomic function in PD, which included control data. Evidence of parasympathetic dysfunction include heart rate (HR) changes after standing up, ${ }^{141819}$ after forced breathing, 9101214 and after the Valsalva manoeuvre. ${ }^{311141518}$ Abnormal sympathetic function tests included abnormal blood pressure (BP) response to standing up, ${ }^{68151819}$ and to sustained handgrip..$^{912} 1419$

The cause of autonomic dysfunction in PD may be PD related damage to areas known to be involved in autonomic regulation. Lewy bodies, sometimes associated with neuronal loss, can be found in preganglionic structures of the sympathetic as well as the parasympathetic nervous system: the spinal intermediolateral horns, ${ }^{2021}$ the vagal dorsal motor nucleus, ${ }^{20223}$ and the Edinger-Westphal nucleus. ${ }^{24}$ Postganglionic sympathetic neurons in the pre and paravertebral ganglia often contain Lewy bodies. ${ }^{62025}$ Lewy bodies are commonly found in central structures involved in autonomic regulation, such as the
Department of Neurology and Clinical

Neurophysiology

J G van Dijk

J Haan

B Kremer

B J van Hilten

R A C Roos

Department of

Medical Statistics,

University Hospital

Leiden

K Zwinderman

Department of

Neurology, St

Elisabeth Hospital,

Leiderdorp, The

Netherlands

J Haan

Correspondence to:

J $G$ van Dijk, Department of Neurology and Clinical

Neurophysiology, University
Hospital, PO Box 9600 ,

2300 RC Leiden, The

Netherlands.

Received 27 August 1992

and in revised form

22 December 1992

Accepted 11 February 1993
Table 1 Autonomic function in Parkinson's disease

\begin{tabular}{|c|c|c|c|c|c|c|c|c|}
\hline \multirow[b]{2}{*}{ Reference } & \multirow[b]{2}{*}{$\begin{array}{l}\text { Number } \\
\text { of } \\
\text { patients }\end{array}$} & \multicolumn{4}{|c|}{ Parasympathetic tests } & \multicolumn{3}{|c|}{ Sympathetic tests } \\
\hline & & $\begin{array}{l}\text { HR } \\
\text { variability } \\
\text { rest }\end{array}$ & $\begin{array}{l}H R \\
\text { during } \\
D B\end{array}$ & $\begin{array}{l}\text { HR after } \\
\text { standing } \\
\text { up }\end{array}$ & $\begin{array}{l}\text { HR after } \\
\text { valsalva }\end{array}$ & $\begin{array}{l}\text { BP fall after } \\
\text { standing/ } \\
\text { tilting }\end{array}$ & $\begin{array}{l}\text { BP after } \\
\text { sustained } \\
\text { handgrip }\end{array}$ & Remarks \\
\hline $\begin{array}{r}5 \\
9 \\
10 \\
11 \\
12 \\
14\end{array}$ & $\begin{array}{l}20 \\
20 \\
14 \\
31 \\
22 \\
30\end{array}$ & $\begin{array}{l}\text { NP } \\
\text { NP } \\
\text { normal } \\
\text { NP } \\
\text { normal } \\
\text { normal }\end{array}$ & $\begin{array}{l}\text { NP } \\
\text { abnormal } \\
\text { abnormal } \\
\text { NP } \\
\text { abnormal } \\
\text { abnormal }\end{array}$ & $\begin{array}{l}\text { NP } \\
\text { normal } \\
\text { NP } \\
\text { NP } \\
\text { normal } \\
\text { abnormal }\end{array}$ & $\begin{array}{l}\text { NP } \\
\text { normal } \\
\text { normal } \\
\text { abnormal } \\
\text { normal } \\
\text { abnormal }\end{array}$ & $\begin{array}{l}\text { abnormal } \\
\text { normal } \\
\text { NP } \\
\text { normal } \\
\text { normal } \\
\text { normal }\end{array}$ & $\begin{array}{l}\text { NP } \\
\text { abnormal } \\
\text { NP } \\
\text { NP } \\
\text { abnormal } \\
\text { systolic } \\
\text { normal; } \\
\text { diastolic } \\
\text { abnormal }\end{array}$ & $\begin{array}{l}- \\
1 \\
- \\
2 \\
3 \\
4\end{array}$ \\
\hline $\begin{array}{l}15 \\
19 \\
18\end{array}$ & $\begin{array}{l}24 \\
26 \\
20\end{array}$ & $\begin{array}{l}\text { see remark } \\
\text { normal } \\
\text { abnormal }\end{array}$ & $\begin{array}{l}\text { NP } \\
\text { normal } \\
\text { NP }\end{array}$ & $\begin{array}{l}\text { NP } \\
\text { abnormal } \\
\text { abnormal }\end{array}$ & $\begin{array}{l}\text { abnormal } \\
\text { normal } \\
\text { abnormal }\end{array}$ & $\begin{array}{l}\text { see remark } \\
\text { abnormal } \\
\text { abnormal }\end{array}$ & $\begin{array}{l}\text { NP } \\
\text { abnormal } \\
\text { NP }\end{array}$ & $\begin{array}{l}5 \\
6 \\
7\end{array}$ \\
\hline
\end{tabular}

Reports were selected in which both a patient and a control group had been investigated. Only data on the most commonly used autonomic tests (HR variation at rest, during deep breathing, following standing up, during a Valsalva manoeuvre, and blood pressure changes following standing up and during sustained handgrip) are presented. Reference $=$ number of citation in presen paper, $\mathrm{PD}=$ Parkinson's disease, $\mathrm{HR}=$ heart rate, $\mathrm{BP}=$ blood pressure, $\mathrm{NP}=$ not performed, $\mathrm{DB}=$ hyperventilation $/$ deep breathing.

Remarks concerning the separate investigations are: $1=$ no effect $L$-dopa; $2=$ no difference on off; $3=$ no effect $L$-dopa; $4=$ no effect L-dopa, no effect of severity, effect of duration on HR after HV; $5=\mathrm{HR}$ variability normal in recent onset PD, abnormal in advanced PD. BP after standing normal in recent PD, abnormal in advanced PD. BP after standing enhanced by $L-d o p a ; 6=P D$ investigated as control group for progressive supranuclear palsy; 7 = effect L-dopa on HR, no effect L-dopa on BP, effect of severity and duration on HR. 
locus coeruleus, the raphe nuclei, the parabrachial area, various other pontine and mesencephalic structures, and the hypothalamus. 202223262728

Many investigators have tried to relate the severity of autonomic dysfunction to clinical aspects of PD. Relationships between autonomic disturbances and disease duration, disease severity, and the use of medication have been investigated, but results have been variable (table 1). The diversity of the conclusions can probably be attributed to relatively small study samples, the largest series comprising 31 patients. Inclusion of patients with Shy-Drager syndrome might have confused the issue of autonomic abnormalities in idiopathic PD. An additional problem may lie in the probable mutual interrelations of these variables and the effect of age, making it difficult to unravel their effects on autonomic function.

We studied autonomic function in $67 \mathrm{PD}$ patients to establish which clinical variables are related to autonomic dysfunction in PD and to which degree, taking into account such confounding effects.

\section{Subjects and methods}

PATIENTS AND CONTROLS

Over a 4 year period, autonomic function was studied in 90 outpatients with idiopathic PD. Patients with cardiac arrhythmia $(n=8)$, hypertension (systolic pressures over $180 \mathrm{~mm}$ $\mathrm{Hg}$ or diastolic pressures over $90 \mathrm{~mm} \mathrm{Hg} ; \mathrm{n}=$ 2) and patients taking medication known to influence autonomic nervous function (except for anti-Parkinson drugs) were excluded ( $n=$ 17). None of the patients had reported autonomic complaints, and no patients in this period were suspected of having Shy-Drager syndrome. Owing to combinations of these factors, 23 patients were excluded; thus 67 PD patients were studied (39 men, 28 women, mean age [SD]: $64 \cdot 8$ [11.1] years, range 41-86 years). Mean duration of $P D$ was 3.38 years (SD: 3.60 years, range $0.5-22$ years). Clinical severity was scored according to the Hoehn and Yahr (HY) scale: 7 patients were at stage I, 28 at stage II, 21 at stage III, 10 at stage $\mathrm{IV}$, and 1 at stage V. Medications were used alone or in combination: levodopa was used by 22 patients (for a mean of 48.6 [47.2] months), amantadine by 17 , bromocriptine by 5 , and anticholinergics by 3 patients. A total of 34 patients were receiving medication; the remaining 33 patients did not use any anti-Parkinson medication. Patients answered a questionnaire on autonomic symptoms.

Thirty one age-matched controls were selected from a database of healthy subjects, ${ }^{29}$ and studied with the same battery of tests. Age of the controls (mean 65.1 [13.5] years, range 42-90) did not differ from that of $P D$ patients (two sided $t$ test, $\mathrm{p}=0.91$ ). PD patients were studied before, during, and after the period in which the controls were tested. The study was approved by the hospi- tal's medical ethics committee, and the subjects gave informed consent.

\section{AUTONOMIC TESTS}

Autonomic nervous function was investigated as previously described. ${ }^{1929-31}$ Four mainly parasympathetic tests were applied; HR variation at rest, during forced breathing at 6-8 breaths per minute, following active standing up (modified 30:15 ratio), and during a Valsalva manoeuvre. ECG R-R intervals were measured by computer, converted to frequencies, and the difference (beats/min) between the maximum and the minimum frequencies during each test was noted. Differences rather than ratios were chosen to describe heart rate changes, because differences are less subject to influences of the resting heart rate. ${ }^{29}$ Two mainly sympathetic tests were applied: the BP response to actively standing up was quantified as the largest drop in systolic and diastolic pressure $(\mathrm{mm} \mathrm{Hg}) 1$ or 2 minutes after standing up. The largest increases in systolic and diastolic pressure during a 5 minute period of sustained hand grip (or until the subjects gave up) at $30 \%$ of maximum voluntary force were also noted. The mean $\mathrm{HR}$ at rest was noted, as were baseline BPs.

\section{STATISTICAL ANALYSIS}

The two sided $t$ test (allowing for unequal variances), analysis of variance, or $\chi^{2}$ tests were applied to investigate differences. Multivariate analysis of covariance was used to study differences in relationships with age between PD patients and controls. Bivariate regression and stepwise forward multiple regression techniques were applied to analyse the dependence of autonomic tests on clinical variables. Results of linear regression are presented with $p$ values as well as with the percentage of variance explained by a relationship, expressed as the squared correlation coefficient multiplied by $100\left(100 \mathrm{R}^{2}\right)$. A $p=0.05$ significance threshold was applied for all tests. Analyses were performed using the statistical packages NCSS (Kaysville, UT) and SPSS (Chicago, IL).

The analysis was performed at different levels. First of all, results of the eight autonomic function variables (four HR tests and both diastolic and systolic pressures of the two BP tests) were compared between the PD and control groups. Secondly, the influences of age and of the three PD related variables (that is, duration of disease, use of anti-Parkinson medication, and disease severity $(\mathrm{HY})$ on autonomic function were investigated in the PD group. Thirdly, an attempt was made to disentangle the effects of these variables on autonomic function, but before this, the interrelations between these variables were assessed. For all eight autonomic variables, two physiological variables (age and either baseline BP or HR) and the three PD related variables were selected for possible inclusion in a stepwise forward regression analysis. Baseline HR or BP was included because these variables can influence autonomic responsiveness. ${ }^{29}$ Systolic BP was 
Table 2 Comparison of Parkinson patients and controls

\begin{tabular}{|c|c|c|c|}
\hline & $\begin{array}{l}P D \text { patients } \\
(n=67)\end{array}$ & $\begin{array}{l}\text { Controls } \\
(n=31)\end{array}$ & p Value \\
\hline $\begin{array}{l}\text { age (years) } \\
\text { systolic BP (mm Hg) } \\
\text { diastolic BP }(\mathrm{mm} \mathrm{Hg}) \\
\text { heart rate (beats } / \mathrm{min}) \\
\text { Heart rate tests (beats/min): }\end{array}$ & $\begin{array}{r}64 \cdot 8(11 \cdot 1) \\
135 \cdot 1(18 \cdot 1) \\
84 \cdot 6(11 \cdot 6) \\
77 \cdot 9(12 \cdot 3)\end{array}$ & $\begin{array}{c}65 \cdot 1(13 \cdot 5) \\
135 \cdot 4(14 \cdot 7) \\
82 \cdot 0(6 \cdot 5) \\
81 \cdot 0(14 \cdot 4)\end{array}$ & $\begin{array}{l}0.913 \\
0.937 \\
0.162 \\
0.318\end{array}$ \\
\hline $\begin{array}{l}\text { at rest } \\
\text { deep breathing } \\
\text { standing up } \\
\text { Valsalva }\end{array}$ & $\begin{array}{l}11 \cdot 1(8 \cdot 2) \\
13 \cdot 9(9 \cdot 0) \\
8 \cdot 7(8 \cdot 9) \\
22 \cdot 5(21 \cdot 4)\end{array}$ & $\begin{array}{l}14 \cdot 0(13 \cdot 3) \\
15 \cdot 5(10 \cdot 8) \\
12 \cdot 2(10 \cdot 2) \\
25 \cdot 8(14 \cdot 9)\end{array}$ & $\begin{array}{l}0 \cdot 324 \\
0 \cdot 485 \\
0 \cdot 122 \\
0 \cdot 430\end{array}$ \\
\hline $\begin{array}{l}\text { BP tests (mm Hg): } \\
\text { syst fall, standing up } \\
\text { diast fall, standing up } \\
\text { syst rise, sust grip } \\
\text { diast rise, sust grip }\end{array}$ & $\begin{array}{l}13 \cdot 7(16 \cdot 7) \\
5 \cdot 2(9 \cdot 7) \\
20 \cdot 6(15 \cdot 1) \\
16 \cdot 6(16 \cdot 0)\end{array}$ & $\begin{array}{c}6 \cdot 4(9 \cdot 7) \\
0 \cdot 0(5 \cdot 0) \\
32 \cdot 6(20 \cdot 4) \\
27 \cdot 0(17 \cdot 8)\end{array}$ & $\begin{array}{l}\frac{0 \cdot 008}{0 \cdot 001} \\
\underline{0 \cdot 005} \\
\underline{0 \cdot 008}\end{array}$ \\
\hline
\end{tabular}

All variables are expressed as mean (SD). $\mathrm{p}$ values refer to two sided $t$ tests with allowances for unequal variances. $\mathrm{p}$ values $<0.05$ : bold type, $\mathrm{p}<0.01$ : bold and underlined. 'Syst' $=$ systolic, 'diast' = diastolic, 'sust' = sustained hand grip.

included when systolic changes were studied, and diastolic BP was included when diastolic changes were studied.

\section{Results}

DIFFERENCES BETWEEN PD AND CONTROL SUBJECTS

Characteristics of the PD and control groups are summarised in table 2 . Age, resting HRs, and resting BPs did not differ between the groups. HR appeared less responsive in the PD group, but the difference was not significant in any of the HR tests. The BP tests showed highly significant differences between the groups, PD patients again performing worse than controls. The questionnaire revealed that $62 \%$ of PD patients experienced dizziness on rising with a frequency of seven [12] times per week. Neither fainting nor other autonomic complaints were observed.

\section{AGE, CLINICAL VARIABLES, AND AUTONOMIC} FUNCTION

Baseline HR and BPs were not significantly influenced by any of the PD related variables. In contrast, HR tests showed a decrease with age in both groups (table 3). Although the decrease with age appeared to be more pronounced in PD patients than in normal subjects, the difference in relationships with age was only significant for the standing up test $(p=0.002)$. In both groups, age exerted a moderate influence on the BP fall on standing, while the BP rise on sustained handgrip was significantly related to age in both groups. Relationships with age did not differ significantly between the groups in any of the BP tests.

To study the effect of the HY stage, stages I and II were combined, and the patient in stage $\mathrm{V}$ was grouped with stage $\mathrm{IV}$, resulting in stages I/II, III, and IV/V. An increasing HY stage had a consistently detrimental effect on autonomic function, which reached significance for three of the four HR tests and for the BP fall on standing (table 4, figure 1).

The only autonomic variable with which disease duration showed any significant correlation was the systolic BP fall on standing up $\left(\mathrm{p}=0.016,100 \mathrm{R}^{2}=9.2 \%\right) ; 100 \mathrm{R}^{2}$ reached a maximum of only $5.0 \%$ for the other variables.

The effects of anti-Parkinson medication were assessed by comparing the medicated with the unmedicated group. Significant differences were found for two HR tests (standing up and Valsalva) and for systolic as well as diastolic BPs in both BP tests (fig 2). In all comparisons, including the non-significant ones, the use of anti-Parkinson medication was related to poorer autonomic responsiveness. The effects of levodopa (22 users and 45 non-users) and amantadine (17 users and 50 non-users) were assessed separately, after showing that there was no correlation in the use of these drugs ( $\chi^{2}$ test, $p=0 \cdot 8$ ). Results for both drugs were similar to those obtained for all medications combined, except for a difference between the effects of these two drugs in the Valsalva test: levodopa users showed a decreased responsiveness compared with non-users. In contrast, results of this test did not differ between amantadine users and non users.

\section{DISENTANGLING THE EFFECTS OF CLINICAL VARIABLES}

Interrelations between age and the three PD related variables were assessed (with linear regression or $\chi^{2}$ tests) to bring to light any potentially confounding effects on the above mentioned relationships. Of the six possible bivariate relationships, four proved to be significant. As expected, older patients were in higher HY stages $\left(p=0.001,100 R^{2}=16 \%\right)$; disease duration was longer in those using anti-Parkinson medication $\left(\mathrm{p}=0.001,100 \mathrm{R}^{2}\right.$ $=16 \%$ ), and in those with higher $\mathrm{HY}$ stages $\left(p=0.003,100 R^{2}=13 \%\right)$. Patients using

Table 3 Effects of age

\begin{tabular}{|c|c|c|c|c|c|c|c|c|}
\hline & \multicolumn{4}{|l|}{ Controls } & \multicolumn{4}{|c|}{ PD patients } \\
\hline & $a$ & $b$ & $p$ & $100 R^{2}$ & $a$ & $b$ & $p$ & $100 R^{2}$ \\
\hline $\begin{array}{l}\text { Heart rate (beats } / \mathrm{min} \text { ): } \\
\text { resting } \\
\text { deep breathing } \\
\text { standing up } \\
\text { Valsalva }\end{array}$ & $\begin{array}{r}-0.39 \\
-0 \cdot 14 \\
0 \cdot 12 \\
-0.64\end{array}$ & $\begin{array}{r}40 \cdot 8 \\
25 \cdot 4 \\
4 \cdot 0 \\
69 \cdot 2\end{array}$ & $\begin{array}{l}0.076 \\
0.434 \\
0.495 \\
0.007 \\
\end{array}$ & $\begin{array}{r}13 \\
3 \\
2 \\
27\end{array}$ & $\begin{array}{l}-0.24 \\
-0.41 \\
-0.43 \\
-1 \cdot 11\end{array}$ & $\begin{array}{l}26 \cdot 8 \\
40 \cdot 3 \\
36 \cdot 8 \\
93 \cdot 9\end{array}$ & $\begin{array}{l}0 \cdot 012 \\
\underline{0 \cdot 000} \\
\underline{0 \cdot 000} \\
\underline{0 \cdot 000} \\
\end{array}$ & $\begin{array}{l}10 \\
24 \\
27 \\
31\end{array}$ \\
\hline $\begin{array}{l}\text { BP tests (mm Hg): } \\
\text { syst fall, standing up } \\
\text { diast fall, standing up } \\
\text { syst rise, sust grip } \\
\text { diast rise, sust grip }\end{array}$ & $\begin{array}{r}0.25 \\
0.09 \\
-0.74 \\
-0.14\end{array}$ & $\begin{array}{r}-9 \cdot 6 \\
-6 \cdot 0 \\
80 \cdot 8 \\
36 \cdot 3\end{array}$ & $\begin{array}{l}0.064 \\
0.179 \\
0.005 \\
0.562\end{array}$ & $\begin{array}{r}12 \\
6 \\
24 \\
1\end{array}$ & $\begin{array}{r}0 \cdot 22 \\
0 \cdot 20 \\
-0 \cdot 31 \\
-0.68\end{array}$ & $\begin{array}{r}-0 \cdot 3 \\
-7 \cdot 9 \\
40 \cdot 6 \\
60 \cdot 7\end{array}$ & $\begin{array}{l}0.244 \\
0.056 \\
0.066 \\
\underline{0.000} \\
\end{array}$ & $\begin{array}{r}2 \\
6 \\
5 \\
23\end{array}$ \\
\hline
\end{tabular}

Relationships of autonomic variables and age (in years) were assessed using bivariate linear regression. The variables a and $b$ refe to the formula of the line of best fit $y=a x+b$. 'p' Refers to the significance of the relationship within each group, expressed as in Table 2. " $100 \mathrm{R}^{2}$ ' describes the percentage of variance of an autonomic variable which is explained by age. Abbreviations as in Table 2 . 
Table 4 Effects of the Hoehn and Yahr (HY) stage on autonomic variables

\begin{tabular}{|c|c|c|c|c|}
\hline & $\begin{array}{l}H Y I / I I \\
n=35\end{array}$ & $\begin{array}{l}H Y I I I \\
n=21\end{array}$ & $\begin{array}{l}H Y I V I V \\
n=11\end{array}$ & $p$ value \\
\hline $\begin{array}{l}\text { Heart rate (beats/min): } \\
\text { resting } \\
\text { deep breathing } \\
\text { standing up } \\
\text { Valsalva }\end{array}$ & $\begin{array}{l}13 \cdot 0(9 \cdot 9) \\
16 \cdot 4(10 \cdot 2) \\
11 \cdot 4(9 \cdot 9) \\
27 \cdot 4(19 \cdot 6)\end{array}$ & $\begin{array}{c}9 \cdot 8(5 \cdot 5) \\
12 \cdot 3(6 \cdot 6) \\
7 \cdot 7(7 \cdot 2) \\
23 \cdot 1(25 \cdot 2)\end{array}$ & $\begin{array}{l}7 \cdot 5(4 \cdot 5) \\
8 \cdot 0(5 \cdot 0) \\
2 \cdot 1(2 \cdot 8) \\
5 \cdot 2(4 \cdot 8)\end{array}$ & $\begin{array}{l}0 \cdot 14 \\
0 \cdot 03 \\
0 \cdot 01 \\
0 \cdot 02\end{array}$ \\
\hline $\begin{array}{l}\text { BP tests (mm Hg): } \\
\text { syst fall, standing up } \\
\text { diast fall, standing up } \\
\text { syst rise, sust grip } \\
\text { diast rise, sust grip }\end{array}$ & $\begin{array}{c}9 \cdot 6(12 \cdot 4) \\
2 \cdot 5(7 \cdot 9) \\
24 \cdot 0(14 \cdot 8) \\
21 \cdot 1(19 \cdot 4)\end{array}$ & $\begin{array}{c}14 \cdot 0(17 \cdot 8) \\
7 \cdot 2(9 \cdot 9) \\
19 \cdot 7(15 \cdot 7) \\
12 \cdot 9(11 \cdot 2)\end{array}$ & $\begin{array}{l}25 \cdot 8(21 \cdot 5) \\
9 \cdot 2(12 \cdot 7) \\
12 \cdot 0(12 \cdot 3) \\
10 \cdot 6(5 \cdot 2)\end{array}$ & $\begin{array}{l}0.02 \\
0.07 \\
0 \cdot 08 \\
0 \cdot 08\end{array}$ \\
\hline
\end{tabular}

HY stage I was grouped with II, and IV with V. Mean value (SD) are given for the three resulting stages; $p$ values (expressed as in Table 2) refer to ANOVA. Abbreviations as in Table 2.

medication were in higher HY stages $(p=$ $0.01)$. Although the age-medication relationship proved to be non-significant, the mean age of non-medicated patients was lower than that of medicated patients $(63 \cdot 3[11 \cdot 4]$ and $66.2[10.9]$ respectively). This pattern of interrelations with, on the one hand, young, unmedicated patients with moderately severe PD of short duration, and on the other hand, medicated patients with more severe PD of
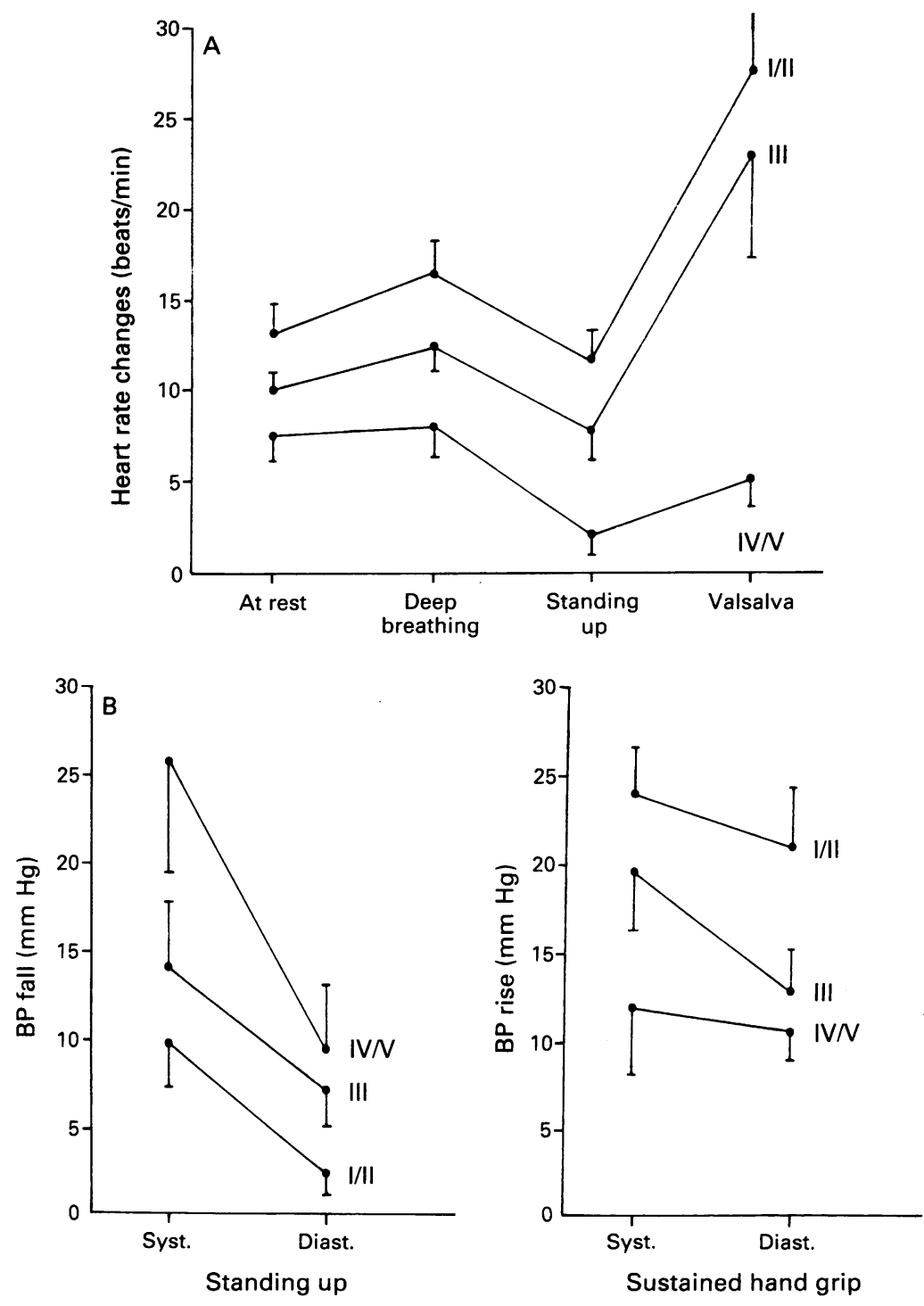
Figure 1 Autonomic function and clinical severity. Results of heart rate tests $(A)$ and
blood pressure tests (B) for three Hoehn and Yahr $(H Y)$ (stages I and II, and $I V$, and $V$ were combined). Bars indicate SEM. Diminished autonomic reactivity is apparent as lower $H R$ changes and as a lower BP rise in the sustained hand grip tests, and as a large $B P$ fall in the standing up BP test. Lowered responsiveness is related to higher $H Y$ stages. longer duration, means that these variables can have strong confounding effects.

The results of the stepwise regression analysis are shown in table 5. Most of the variance of $H R$ tests was explained by age, which consistently affected all four HR tests. Baseline HR reached significance once (standing up test). The use of medication was the only specific PD related variable to emerge as a significant factor, but this only explained a modest degree of variance, and held only for the standing up and Valsalva HR tests. None of the PD related factors had a significant effect on $H R$ changes at rest or during deep breathing.

A smaller degree of overall variance could be explained for the BP tests than for the HR tests. Two factors emerged as significant influences on the diastolic rise in the sustained handgrip test: age and baseline BP. The systolic rise in the same test was only influenced by use of medication. In the standing up test, HY stage influenced both systolic and diastolic BP changes.

Although the use of anti-Parkinson medication was considered to be a PD related variable, the relation is iatrogenic rather than pathophysiological in nature. In view of the importance of medication for autonomic function, the unmedicated PD group was compared with the control group. Age did not differ significantly between the unmedicated PD (63.3 [11.4] years) and the control $(65.1[13.5]$ years) groups. None of the autonomic tests showed significant differences between these groups. A tendency towards significance $(p=0.08)$ was found for the fall in diastolic BP on standing. Within this unmedicated $P D$ group, relationships with age and baseline HRs or BPs were similar to those for the entire PD group. However, no convincing correlations with clinical severity or disease duration could be found.

\section{Discussion}

PD patients consistently showed a diminished autonomic responsiveness compared with healthy controls, although the comparisons reached statistical significance only for BP tests. The evidence of diminished sympathetic (BP) and parasympathetic (HR) activity in PD demonstrated by this study is in accordance with previous findings (table 1 ).

Our work extends earlier studies considerably by offering the ability to analyse the effects of clinical variables of PD in more detail. When the influence of each of these variables on autonomic function was studied without taking any of the other variables into account, we found a detrimental effect of age, use of anti-Parkinson medication, and clinical severity. Disease duration proved to be of little importance. These results confirm some earlier reports, but not all (table 1), probably because of the small number of patients in these reports (less than half of the number in the present study).

Although these bivariate relationships seem straightforward, their explanation is compli- 
Table 5 Forward stepwise regression analysis

\begin{tabular}{|c|c|c|c|c|c|c|c|c|c|c|c|c|c|}
\hline Test & $\begin{array}{l}\text { Step } 1 \\
\text { Var }\end{array}$ & $100 R^{2}$ & $B$ & $S E$ & $\begin{array}{l}\text { Step } 2 \\
\text { Var }\end{array}$ & $100 R^{2}$ & $B$ & $S E$ & $\begin{array}{l}\text { Step } 3 \\
\text { Var }\end{array}$ & $100 R^{2}$ & $B$ & $S E$ & $\begin{array}{l}\text { Total } \\
100 R^{2}\end{array}$ \\
\hline $\begin{array}{l}\text { Heart rate tests: } \\
\text { resting } \\
\text { deep breathing } \\
\text { standing up } \\
\text { Valsalva }\end{array}$ & $\begin{array}{l}\text { age } \\
\text { age } \\
\text { age } \\
\text { age }\end{array}$ & $\begin{array}{l}29 \cdot 5 \\
24.6 \\
25.9 \\
36.0\end{array}$ & $\begin{array}{l}-0.33 \\
-0.42 \\
-0.40 \\
-0.93\end{array}$ & $\begin{array}{l}0.07 \\
0.10 \\
0.09 \\
0.19\end{array}$ & $\begin{array}{l}\overline{\overline{H R}} \\
\text { med }\end{array}$ & $\begin{array}{l}\overline{7} \\
6.8 \\
6.5\end{array}$ & $\begin{array}{l}\bar{z} \\
-0.19 \\
9.82\end{array}$ & $\begin{array}{l}\overline{-} \\
\overline{0.08} \\
4 \cdot 10\end{array}$ & $\overline{\overline{\text { med }}}$ & $\frac{\overline{7}}{5 \cdot 6}$ & $\begin{array}{l}\overline{4} \\
\overline{4} 46\end{array}$ & $\frac{\bar{z}}{2 \cdot 05}$ & $\begin{array}{l}29 \cdot 5 \\
24 \cdot 6 \\
38 \cdot 3 \\
42 \cdot 5\end{array}$ \\
\hline Test & $\begin{array}{l}\text { Step } 1 \\
\text { Var }\end{array}$ & $100 R^{2}$ & $B$ & $S E$ & $\begin{array}{l}\text { Step } 2 \\
\text { Var }\end{array}$ & $100 R^{2}$ & $B$ & & $S E$ & & & & $\begin{array}{l}\text { Total } \\
100 R^{2}\end{array}$ \\
\hline $\begin{array}{l}\text { Blood pressure test } \\
\text { Standing up } \\
\text { syst fall } \\
\text { diast fall }\end{array}$ & $\begin{array}{l}\mathrm{HY} \\
\mathrm{HY}\end{array}$ & $\begin{array}{r}12 \cdot 7 \\
9 \cdot 7\end{array}$ & $\begin{array}{l}7 \cdot 30 \\
3 \cdot 79\end{array}$ & $\begin{array}{l}2.46 \\
1.48\end{array}$ & - & 二 & 二 & & $\bar{z}$ & & & & $\begin{array}{r}12 \cdot 7 \\
9 \cdot 7\end{array}$ \\
\hline $\begin{array}{l}\text { syst rise } \\
\text { diast rise }\end{array}$ & $\begin{array}{l}\text { med } \\
\text { age }\end{array}$ & $\begin{array}{l}10 \cdot 6 \\
24 \cdot 0\end{array}$ & $\begin{array}{r}9.93 \\
-0.79\end{array}$ & $\begin{array}{l}3.76 \\
0.17\end{array}$ & $\overline{\mathrm{BP}}$ & $\overline{5 \cdot 7}$ & $\overline{-0}_{34}$ & & $\overline{0 \cdot 15}$ & & & & $\begin{array}{l}10 \cdot 6 \\
29.7\end{array}$ \\
\hline
\end{tabular}

Three PD related variables (use of anti-Parkinson medication (med), Hoehn and Yahr stage (HY) and duration of disease) were considered for inclusion in the regression model. The physiological variables age and the baseline heart rate (HR) were considered for heart rate tests, and the baseline blood pressure (BP) for BP tests (diastolic baselines for diastolic changes; similar for systolic values). Variables (var) are presented in the order of selection (step) and thus of the significance of their relationship with the autonomic variable. Presented are squared part correlation coefficients multiplied by $100\left(100 R^{2}\right)$; these represent the percentage of the total variance of the autonomic variable which is additionally explained by inclusion of the variable. " $\mathrm{B}$ " is the regression coefficient, and SE the corresponding standard error. 'Total' represents the percentage of variance explained by the selected combination of variables. Abbreviations as in Table 2 .
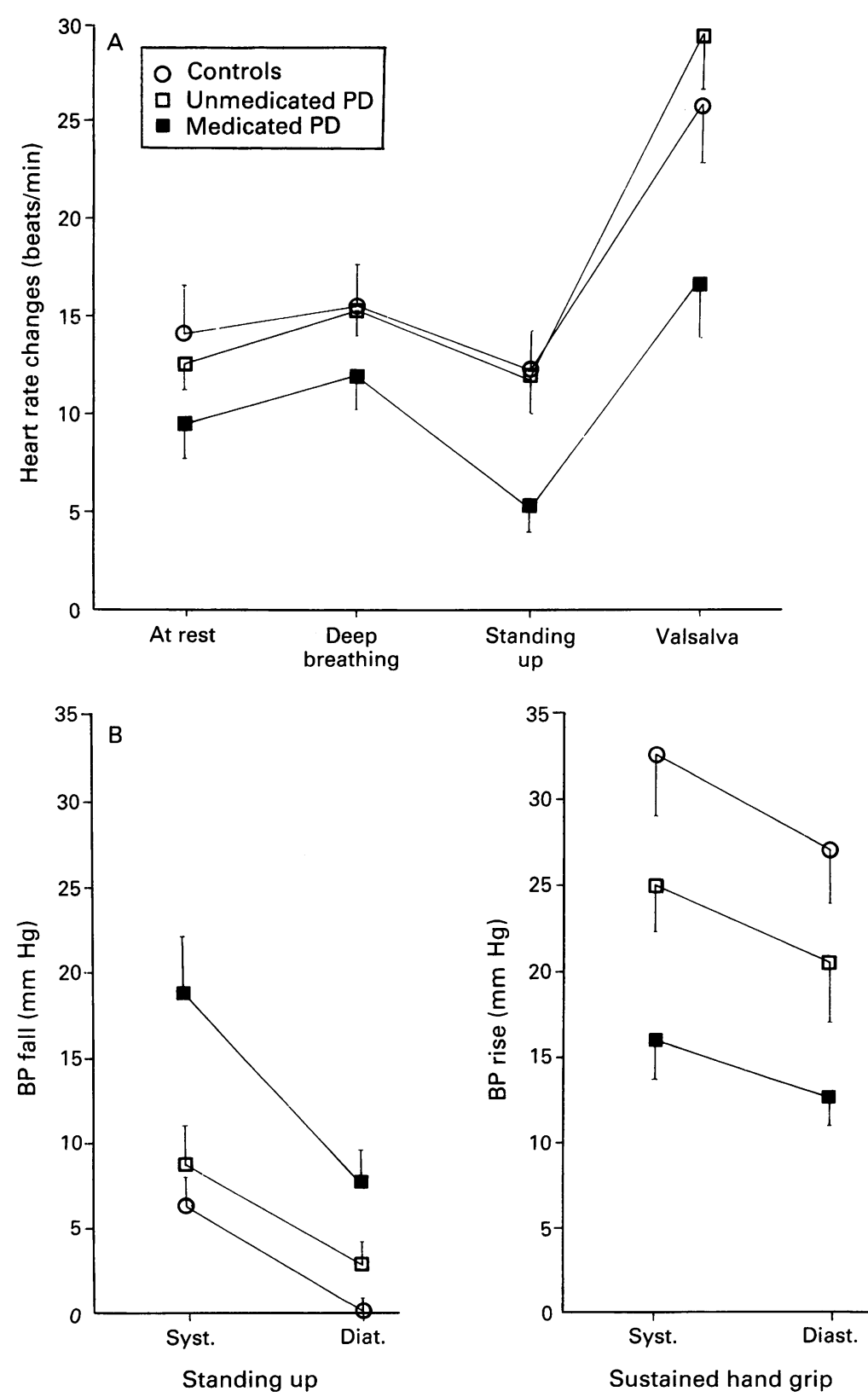

Figure 2 Autonomic function and anti-Parkinson medication. Heart rate $(A)$ and blood pressure $(B)$ results in $P D$ patients, divided according to the use of anti-Parkinson medication, which leads to impaired autonomic responsiveness. cated by the strong interrelations between age, clinical severity, use of medication, and disease duration. For instance, it is well known that most autonomic functions decrease with age. There was a significant relationship between age and the HY stage; should the diminished autonomic reactivity found for higher HY stages be attributed to age, or to progressive damage caused by PD itself?

Stepwise forward regression was used in an attempt to disentangle such effects. Clinical severity, duration of disease, and the use of medication were selected as potentially relevant $\mathrm{PD}$ related variables. To these were added age as well as a baseline autonomic variable (either heart rate or $\mathrm{BP}$ ), as earlier findings had indicated. ${ }^{29}$

Only modest portions of the variance of autonomic tests could be explained by the PD related variables. For HR tests, age explained the majority or even all of the accountable amount of variance. When the effects of physiological (age and baseline HR) and iatrogenic (medication) variables were taken into account, no effects of the specific $P D$ variables (HY and duration) could be ascertained for HR tests. The same reasoning applies to the sustained handgrip BP test. However, for the standing up BP test, the HY stage did have a significant effect, although this was limited in magnitude, reaching a maximum of $12.7 \%$ of explained variance.

The relatively large size of the unmedicated PD group enabled one to study autonomic function with one less confounding variable. No significant differences were found between unmedicated PD patients and controls. Within this group, autonomic tests were not related to clinical variables - that is, disease duration or clinical severity. There was no statistically convincing evidence that autonomic dysfunction occurred in unmedicated PD. But PD in this group might not be serious enough to result in a noticeable degree of autonomic damage: $\mathrm{PD}$ in the unmedicated PD group proved to be of low severity (21 patients in $\mathrm{HY}$ stage $1 / 2,12$ in stage II, and 1 in stage IV/V; difference with medicated PD 
group: $\mathrm{p}=0.01)$, and short duration $(2.0$ [1.9] years, compared with $4 \cdot 8[4.3]$ years of the medicated PD group: $p=0.002$ ). The results of this study suggest that autonomic dysfunction is limited to the BP response to standing up, that this is restricted to more severe $\mathrm{PD}$, and even then remains modest in severity. As such, our findings strengthen Bannister's conclusion regarding the paucity of cardiovascular autonomic dysfunction in $\mathrm{PD}^{32}$ with detailed evidence.

The evaluation of cardiovascular autonomic dysfunction in PD is easily confounded by interrelated variables, the most important being age and the use of antiParkinson medication. A failure to compensate for such factors may lead to the erroneous conclusion that the frequently occurring disturbance of autonomic tests in $P D$ is entirely due to PD, whereas PD itself appears to cause only modest damage to the antonomic nervous system.

1 Calne DB, Brennan J, Spiers ASD, Stern GM Hypotension caused by L Dopa. BMF 1970;1:474-5.

2 Aminoff MJ, Wilcox CS. Assessment of autonomic function in patients with a parkinsonian syndrome. $B M \mathcal{F}$ tion in patients

3 Appenzeller O, Goss JE. Autonomic deficits in Parkinson's syndrome. Arch Neurol 1971;24:50-7.

4 Reid JL, Calne DB, Gearge CF, et al. Cardiovascular reflexes in parkinsonism. Clin Sci 1971;41:63-7.

5 Gross M, Bannister R, Godwin-Austen R. Orthostatic hypotension in Parkinson's disease. Lancet 1972; $174-6$

6 Rajput AH, Rozdilsky B. Dysautonomia in parkinsonism a clinicopathological study. $\mathcal{f}$ Neurol Neurosur Psychiatry 1976;39:1092-100.

7 Kuroiwa Y, Shimada Y, Toyokura Y. Postural hypotension and low $R-R$ interval variability in parkinsonism, spino-cerebellar degeneration, and Shy-Drager syndrome. Neurology 1983;33:463-7.

8 Baratti M, Calzetti S. Fluctuations of arterial blood pressure during end-of-dose akinesia in Parkinson's disease. sure during end-of-dose akinesia in Parkinson's
7 Neurol Neurosurg Psychiatry 1984;47:1241-3.

9 Sachs C, Berglund B, Kaijser L. Autonomic cardiovascular responses in parkinsonism: effect of levodopa with dopa-decarboxylase inhibition. Acta Neurol Scand 1985; 71:37-42.

10 Camerlingho $\mathrm{M}$, Aillon $\mathrm{C}$, Bottacchi E, et al. Parasympathetic assessment in Parkinson's disease. Adv Neurol 1986;45:267-9.

11 Goetz CG, Lutge W, Tanner CM. Autonomic dysfunc- tion in Parkinson's disease. Neurology 1986;36:73-5.

12 Ludin SM, Steiger UH, Ludin HP. Autonomic disturbances and cardiovascular reflexes in idiopathic Parkinson's disease. $\mathcal{F}$ Neurol 1987;235:10-5.

13 Tanner CM, Goetz CG, Klawans HL. Autonomic nervous system disorders. In: Koller WC, ed. Handbook of Parkinson's disease. New York, Basle: Marcel Dekker 1987:145-70.

14 Turkka JT, Tolonen U, Myllyla VV. Cardiovascular reflexes in Parkinson's disease. Eur Neurol 1987;26: reflexes

15 Piha SJ, Rinne JO, Rinne UK, Seppanen A. Autonomic dysfunction in recent onset and advanced Parkinson's dysfunction in recent onset and advanced Park
disease. Clin Neurol Neurosurg 1988;90:221-6.

16 Korezyn $\mathrm{AD}$. Autonomic nervous system dysfunction in Parkinson's disease. In: Calne DB, ed. Parkinsonism and aging. New York: Raven Press 1989:21 1-9.

17 Iwasaki S, Hamaguchi K, Iwasaki A, et al. Hypotensive effect of long-term levodopa in patients with Parkinson's disease. Eur Neurol 1990;30:194-9.

18 Meco G, Pratesi L, Bonifati V. Cardiovascular reflexes and autonomic dysfunction in Parkinson's disease. and Neurol 1991;238:195-9.

19 Dijk JG van, Haan J, Koenderink M, Roos RAC. Autonomic nervous function in progressive supranuclear palsy: A comparison with Parkinson patients and normal controls. Arch Neurol 1991;48:1083-4

20 Hartog Jager WA den, Bethlem J. The distribution of Lewy bodies in the central and autonomic nervous system in idiopathic paralysis agitans. $f$ Neurol Neurosurg Psychiatry 1960;23:283-90.

21 Oppenheimer DR. Lateral horn cells in progressive autonomic failure. F Neurol Sci 1980;46:393-404.

22 Ohama E, Ikuta F. Parkinson's disease: distribution of Lewy bodies and monoamine neuron system. Acta Neuropathol 1976;34:311-9.

23 Jellinger $\mathrm{K}$. The pathology of Parkinsonism. In: Marsden CD, Fahn S, eds. Movement disorders Vol 2. London: Butterworths, 1987:124-65.

24 Hunter S. The rostral mesencephalon in Parkinson's disease and Alzheimer's disease. Acta Neuropathol ease and A 1985 ; 83 . 8 .

25 Forno LS, Norville RL. Ultrastructure of Lewy bodies in the stellate ganglion. Acta Neuropathol 1976;34:183-97.

26 Greenfield JG, Bosanquet FD. The brain-stem lesions in Parkinsonism. F Neurol Neurosurg Psychiatry 1953;16: 312-26.

27 Buttlar-Brentano $\mathrm{K}$ von. Zur Lebensgeschichte der Nucleus basalis, tuberomammillaris, supraopticus, und paraventricularis unter normalen und pathogenen Bedingungen. $\mathcal{F}$ Himforsch 1954;1:337-419.

28 Langston JW, Forno LS. The hypothalamus in Parkinson's Disease. Ann Neurol 1978;3:129-33.

29 Dijk JG van, Koenderink M, Zwinderman AH, et al. Autonomic nervous tests depend on resting heart rate and blood pressure. F Auton Nerv Syst 1991;35:15-24.

30 Heijer JC den, Bollen WLEM, Reulen JPH, et al. Autonomic nervous function in Huntington's disease. Autonomic nervous function

31 Heijer JC den, Dijk JG van, Bollen E, et al. Assessment of autonomic function in myotonic dystrophy. $\mathcal{f}$ Neurol Neurosurg Psychiatry 1991;54:516-9.

32 Bannister $R$. Clinical features of autonomic failure. A. Symptoms, signs and special investigations. In: Bannister R, ed. Autonomic failure. 2nd Ed. Oxford, New York, Tokyo: Oxford University Press 1988: 267-80. 